\title{
Development of Suitable Microclimate Using Low-tech Greenhouse for Off-Season Production of High Value Crops in Bangladesh
}

\author{
M. A. Awal, P. C. Dhar, and M. H. R. Pramanik
}

\section{ABSTRACT}

Low-tech greenhouses (low-techs) have been used globally to cultivate horticultural crops since many years, but their utilization in Bangladesh is a recent phenomenon. Moreover, information on altered microclimate inside the low-tech is hardly reported. An investigation has been conducted in the Crop Botany Field Laboratory, Bangladesh Agricultural University $\left(2^{\circ}{ }^{\circ} 2^{\prime} \mathrm{N}\right.$, $9^{\circ}{ }^{\circ} 3^{\prime} \mathrm{E}$ and $18 \mathrm{masl}$ ), Mymensingh during the late autumn to winter seasons from mid-October to mid-February of 2015/16, 2016/17 and 2017/18 years to find out the variation in microclimatic parameters between inside and outside of low-techs and to evaluate the suitability of altered microclimate inside the low-techs for off-season production of high value crops in Bangladesh. Three low-techs were erected in each year using bamboo frame covered with single inflated polyethylene film (thickness $=0.2 \mathrm{~mm}$ ). Major microclimatic parameters inside and aside outside the low-techs were measured with standard devices or techniques. Around 30 percent incoming photosynthetically active radiation (PAR) was cut-off by low-tech cover during solar noon when the sun's zenith gets minimum value (around $0^{\circ}$ ). However, this cut-off portion of PAR was gradually increased with the sunrise and sunset when zenith is around $9^{\circ}$. During the daytime, low-tech retains higher air temperature than that found at outside and the differences in air temperature between inside and outside of low-techs was gradually increased after sunrise with a peak difference of 7 to $9^{\circ} \mathrm{C}$ following the solar noon (i.e., 13:00-14:00 hour). No distinct variation in relative humidity was recorded between inside and outside of the low-tech. Low-tech cover retains higher soil temperature than that was recorded in outside. The variation of both air and soil temperatures between inside and outside of low-techs was higher during the daytime but lower at nighttime or even at daytime when the sky remained overcast. The variation in microclimatic parameters under low-techs not only protect the growing crops from climate vagaries during autumn, winter and spring seasons but also provide suitable warmer environment for growing many high value crops during that seasons and thus crop production in off-season and/or season extension benefits can easily be achieved by low-techs.

Keywords: Low-tech greenhouse, Microclimate, PAR, Plastic culture, Polytunnel, Relative humidity, Temperature.

\section{INTRODUCTION}

Low-tech greenhouse ('Low-tech') that represents a semicircular, square or elongated structure constructed with bamboo and/or wood and polyethylene film are usually transparent or clear in appearance as a cladding material [1]. It is also known as a hoop greenhouse, hoophouse, high tunnel, polytunnel or polyhouse. It has the advantage of being relatively inexpensive compared to greenhouses. Unlike the hi-tech or professional greenhouses, no particular tool for controlling environmental traits inside the low-tech is given. Recent designs permit sowing and harvesting devices to pass inside the low-tech covers so as to mechanized production. The use of low-tech greenhouse can extend the growing season considerably whether with early cropping at the beginning of the season or extended cropping at the end of the season [2], [3]. In order to provide favourable environment for plant growth and development, cultivation of crops using low-techs and some other related
Submitted : November 12, 2021

Published : December 25, 2021

ISSN: $2684-1827$

DOI: 10.24018 /ejfood.2021.3.6.414

\section{A. Awal*}

Laboratory of Plant Ecology, Department of Crop Botany, Bangladesh Agricultural University, Mymensingh 2202, Bangladesh.

(e-mail: awalma7@bau.edu.bd)

P. C. Dhar

Laboratory of Plant Ecology, Department of Crop Botany, Bangladesh Agricultural University, Mymensingh 2202, Bangladesh.

(e-mail: pdhar890@gmail.com)

M. H. R. Pramanik

Laboratory of Plant Ecology, Department of Crop Botany, Bangladesh Agricultural University, Mymensingh 2202, Bangladesh.

(e-mail: habiburp@yahoo.com)

*Corresponding Author structures is called protected cultivation [4], [5].

Partial control of microclimatic elements like light, temperature, humidity, ventilation, etc. which have a major influence on plant growth and development can be achieved through low-tech greenhouse or polyhouse [6]. Crop productivity can be improved with the low-techs by altering or enhancing daytime light quality and preventing heat loss at night [7]. Low-tech commonly enhances air temperature in the daytime for favorable production of some winter crops providing their continuous supply to markets around the year [8]. So, low-techs are gaining popularity day by day for the production of vegetables and other horticultural crops worldwide [9], [10]. The elevated temperature inside the low-tech reduces the life span by meeting the heat demands or degree days of growing crops. For example, elevated air temperature inside the low-techs directly influences fruit precocity in tomatoes and strawberries with a harvesting time 7 to 21 days earlier compared to the open field [3], [11]-[13]. 
Air temperature often goes below the minimum threshold level for the production of many crops during the late autumn through winter seasons in Bangladesh. Thus, there are huge scopes of using the low-tech technology to elevate air temperature during the winter season for the cultivation of high-value crops like cucumber, tomato, strawberry, watermelon, okra, etc. for getting their premium market price and year round availability in Bangladesh. The low-tech being a low cost technology, farmers can use this affordable technique for the production of horticultural crops. But there exist some knowledge gaps among the stakeholders like scientific communities, extension workers, farmers, etc. in Bangladesh on what extent or magnitude the microclimatic parameters can be modified by the low-tech technology suited for the target crops. A number of studies were conducted worldwide for crop production under low-tech structures but studies on their ability to modify microclimate in detail are quite scanty. Therefore, the present study was carried out to evaluate the microclimatic parameters that can be modified by the low-techs from late autumn through winter seasons in Bangladesh.

\section{MATERIALS AND METHODS}

\section{A. Study Site}

The investigation was carried out at the Field Laboratory of the Department of Crop Botany, Bangladesh Agricultural University (BAU), Mymensingh (24ำ $72^{\prime} \mathrm{N}$ latitude, $90^{\circ} 43^{\prime} \mathrm{E}$ longitude and 18 meter altitude from sea level).

\section{B. Construction of Low-tech Greenhouse}

Three low-techs (each of $7.3 \times 4.3 \mathrm{~m}$ size and represents a replication of the experiment) were constructed on a weed free, leveled and rectangular land. Initially the land required as per size of a low-tech, six points in each side and in the midline between them were marked at equal distance. In each marked point, a $15 \mathrm{~cm}$ diameter hole to a depth of $50 \mathrm{~cm}$ was prepared to evacuate the soil therein to erect $2 \mathrm{~m}$ long bamboo poles in the side holes and $2.7 \mathrm{~m}$ long bamboo poles in the central holes by filling and tightly pressing the soil around them. Thus, the heights in middle (i.e. central) and both sides of a low-tech were $2.2 \mathrm{~m}$ and $1.5 \mathrm{~m}$, respectively. Atop of the central poles, a $7.3 \mathrm{~m}$ long and slender bamboo was fixed longitudinally and then bamboo strips were placed crossing atop long bamboo and fixed them on site pegs in such a way so that the structure becomes a Quonset (D-shape). Some bamboo strips have also been placed both length- and breadth-wise and tied with the structure to provide more strength.

After the erection of the bamboo frame (D-shape), single inflated polyethylene film $0.2 \mathrm{~mm}(200 \mu \mathrm{m})$ thick was spread over the whole structure from one end to another carefully to avoid any puncture or tear in the film. The lower edge of the polyethylene film on both sides was fixed with bamboo strips in such a way so that it could be folded up and down for ventilation in the low-tech when required and the ventilation was furnished particularly to reduce the high humidity in the low-tech. A gate made with polyethylene film and bamboo strips were installed in each low-tech to get in and out of them for necessary operations like plantation, water supply, weeding, data collection, etc.

\section{Data Collection}

Data on microclimatic variables such as photosynthetically active radiation (PAR), air and soil temperatures and relative humidity inside and outside the low-techs were recorded. PAR (in $\mu \mathrm{molm}^{-2} \mathrm{~s}^{-1}$ ) represents about $45 \%$ of solar radiation (in $\mathrm{W} \mathrm{m}^{-2}$ ). A Radiometer (Model LI-189, Li-Cor, Lincoln, NE, USA) connected to a 1 m-long Line Quantum Sensor (SR. NO. LQA 1401, Li-Cor, Lincoln, NE, USA) were used to record the data on the incoming PARs inside and outside of the low-tech. PAR data were collected during cloud-free or blue sky conditions. The percentage of PAR transmission through the low-tech cover was computed by subtracting PAR inside the low-tech from PAR available at the natural outside which was divided by PAR available in the open field and then multiplied by hundred (100). That is:

\section{$\%$ PAR transmission \\ PAR at outside the low tech-PAR at inside the low tech} $=\frac{\text { PAR at outside the low tech }}{\text { PAR a tech }} \times 100$

Air temperature and relative humidity (RH) were recorded with Indoor-Outdoor Digital Thermohygrometers (HTC-1 LCD Digital Thermometer Hygrometer) installed in each low-tech. Soil temperature was recorded at 1, 5, and 10 $\mathrm{cm}$ depths with a glass-made long thermometer covered with stainless steel metal case.

TABLE I: SALIENT Climatic FeAtures of SOME DAys WHEN Microclimatic MEASUREMENTS WERE PERFORMED

\begin{tabular}{cccccc}
\hline Salient features & \multicolumn{5}{c}{ Measurement date $^{\mathrm{a}}$} \\
\cline { 2 - 6 } & 4 Nov 2016 & 19 Nov 2016 & 20 Nov 2015 & 5 Dec 2017 & 10 Dec 2016 \\
\hline Day of year $(\mathrm{DOY})$ & 309 & 324 & 324 & 339 & 345 \\
Air pressure $(\mathrm{mb})$ & 1009 & 1010 & 1012 & 1010 & 1010 \\
Mean temperature $\left({ }^{\circ} \mathrm{C}\right)$ & 27.2 & 21.9 & 24.5 & 21.0 & 21.5 \\
Dew point temperature $\left({ }^{\circ} \mathrm{C}\right)$ & 22.0 & 17.0 & 18.0 & 16.0 & 15.0 \\
Mean water temperature $\left({ }^{\circ} \mathrm{C}\right)$ & 23.9 & 19.4 & 21.5 & 17.9 & 17.5 \\
Mean relative humidity $(\%)$ & 90 & 78 & 78 & 79 & 83 \\
Total rainfall $(\mathrm{mm})$ & 0.00 & 0.00 & 0.00 & 0.00 & 0.00 \\
Mean wind speed $(\mathrm{kmph})$ & 5.38 & 2.13 & 2.16 & 1.63 & 2.98 \\
Sun shine duration $(\mathrm{hr})$ & 0.9 & 8.7 & 8.8 & 8.9 & 6.2 \\
Total solar radiation $\left(\mathrm{W} \mathrm{m}^{-2}\right)$ & 103 & 216 & - & - & 159 \\
Pan evaporation $(\mathrm{mm})$ & 3.5 & 2.6 & 2.5 & 2.2 & 2.5 \\
\hline \hline
\end{tabular}

${ }^{\mathrm{a}}$ Arranged as per sequence of the number of Day of Year (DOY).

Source: Meteorological Observatory of the Bangladesh Meteorological Department collected from the Department of the irrigation and water Management, BAU, Mymensingh. 
All microclimatic parameters were measured at hourly intervals on 5 different days in November and December months of 2015, 2016, and 2017. Salient climatic features of those days are stated in Table I.

\section{Data Analysis}

The collected data analyzed statistically using the MSTAT-C Package Programme [14]. The Least Significant Difference (LSD) was used to compare the means.

\section{RESULTS}

\section{A. Day Time-course of Incident PAR and Light Cut-off by} Low-tech Cover

The sun starts to supply direct radiation on a place in the earth in the morning upon its rising in the east. The amount of incident radiation just after sunrise is very low as it is subjected to travel longer distances through the atmosphere with maximum zenith angle $\left(90^{\circ}\right)$ i.e. sun low in the sky (Fig. 1). With the advancement of day, the sun's zenith angle is minimized along with the sun high in the sky that offers a higher amount of light. The intensity of sunlight gets peaks on solar noon (around 12:00 hour) when it falls almost perpendicularly on the earth (zenith angle $=0^{\circ}$ ). Thereafter the amount of solar radiation gradually decreases to get zero on sunset. On an overcast or cloudy day, there was no distinct pattern of solar radiation with time (Fig. 1a).
On any sunny day, the amount of PAR from sunrise to sunset exhibited a normal distribution pattern as shown in Fig. 1b-e. However, this normal distribution pattern along with the daytime light immediately disrupted if any obstacle like cloud cover has appeared as a barrier on the radiation path as shown in Fig. 1a. The low-tech internally gets a lower amount of solar radiation as compared to that incident outside and the variation was found significant (Fig. 2).

A remarkable portion of solar radiation that incident from sun was cut-off by low-tech cover. This cut-off portion of incident light was found highest during morning time which gradually reduced towards the solar noon (Fig. 3). Thereafter, the percentage of cut-off light steadily increased again towards sunset. That is, the portion of cut-off light by low-tech cover is a function of sun's zenith angle. In other word, it is a function of light quantity and light quality. Direct light or solar beam that maximized at solar noon was less cut-off while the diffuse light that much available at higher zenith angle during morning and following afternoon was highly cut-off by the low-tech cover. Overall, around 30 percent incoming solar radiation was cut-off by low-tech cover at solar noon (Fig. 4) when sun's zenith gets minimum value i.e. around zero. However, this cut-off portion of sunlight was more than 30 percent on the basis of day-time (from sunrise to sunset).
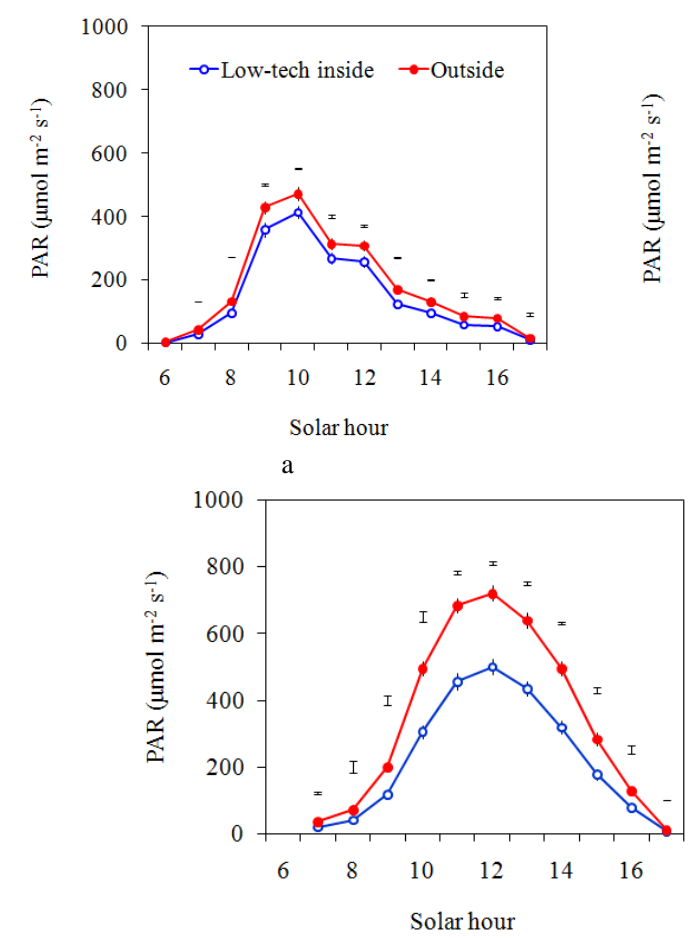

d

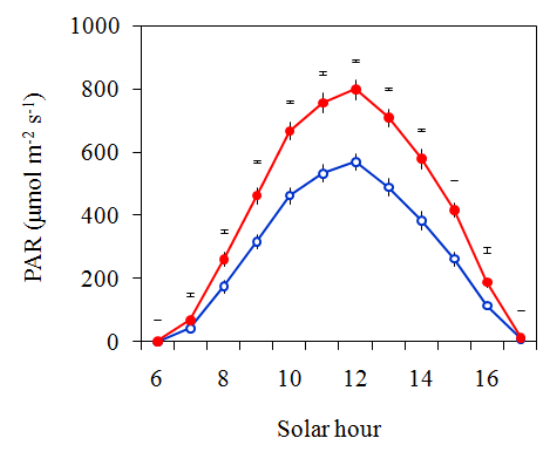

b

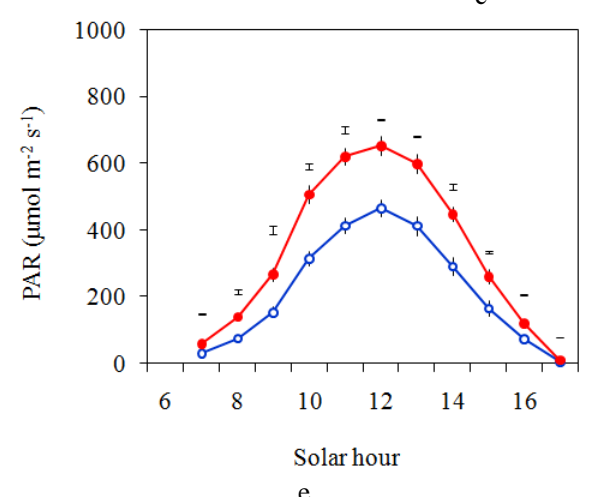

Fig. 1. Day time-course of photosynthetically active radiation (PAR, $\mu \mathrm{mol} \mathrm{m} \mathrm{m}^{-2} \mathrm{~s}^{-1}$ ) inside the low-tech and that at outside at different dates of measurements (a-e). Attached vertical bars (without cap) represent the standard deviation $( \pm)$ of mean $(n=3)$ while detached vertical bars (capped) represent the Least Significant Difference $(\mathrm{LSD})$ at $5 \%$ level of probability $(P<0.05)$. Solar hour refers the Bangladesh Standard Time $=$ Greenwich Mean Time $($ GMT $)+6$ Hours. Overcast sky after $10^{\text {th }}$ hour: (a) 4 November 2016; Fine sky throughout day: (b) 19 November 2016; (c) 20 November 2015;

(d) 5 December 2017; (e) 10 December 2016. The dates are arranged as per the sequence of the number of Day of Year (DOY). 
European Journal of Agriculture and Food Sciences www.ejfood.org

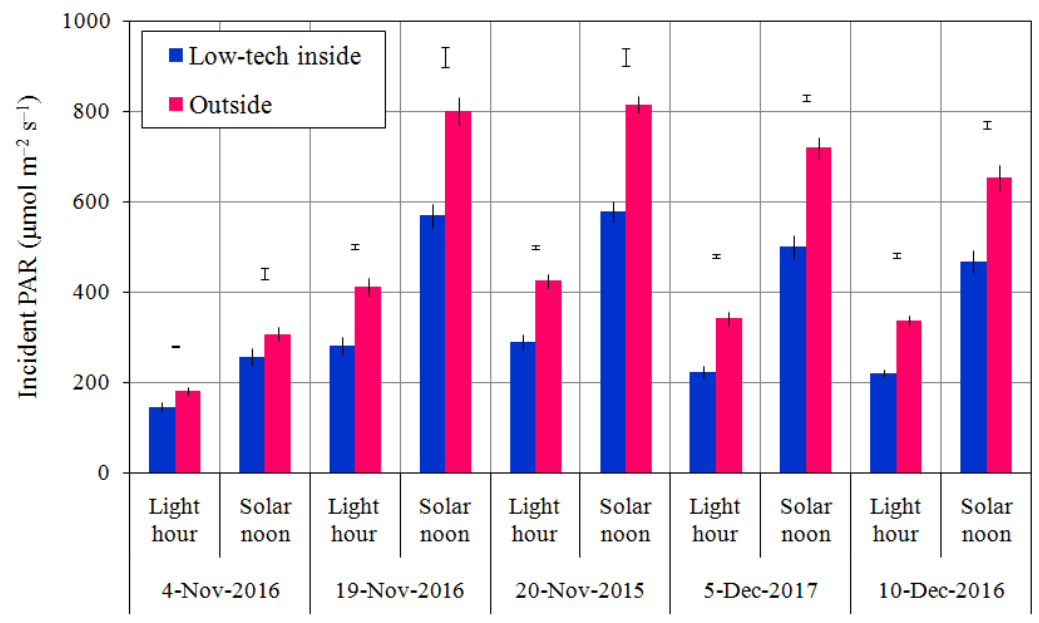

Fig. 2. Incident photosynthetically active radiation (PAR) during solar noon time and that measured throughout the day from sunrise to sunset (i.e. total light hours) at inside the low-tech and that at outside at different dates of measurement. Attached vertical bars (without cap) represent the standard deviation $( \pm$ ) of mean $(n=3)$ while detached vertical bars (capped) represent the Least Significant Difference (LSD) at $1 \%$ level of probability $(P<0.01)$. The dates are arranged as per sequence of the number of Day of Year (DOY). The sky remained overcast after $10^{\text {th }}$ hour on 4-Nov-2016 while the other dates remained fine throughout the day.

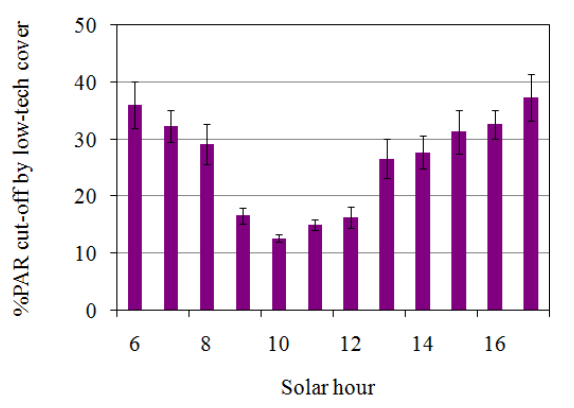

a

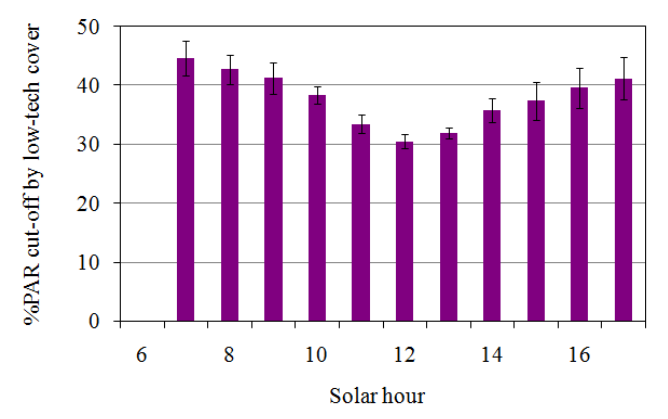

d

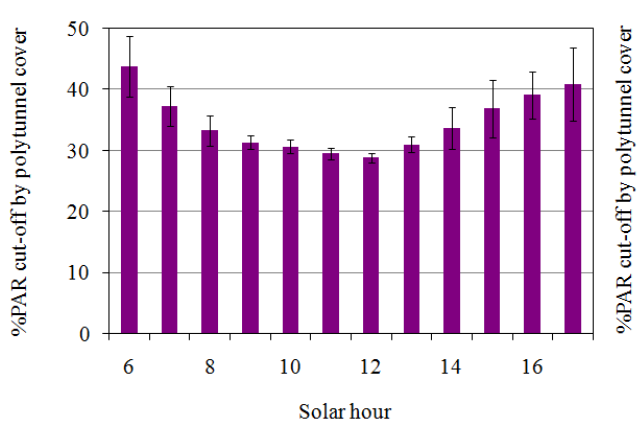

$\mathrm{b}$

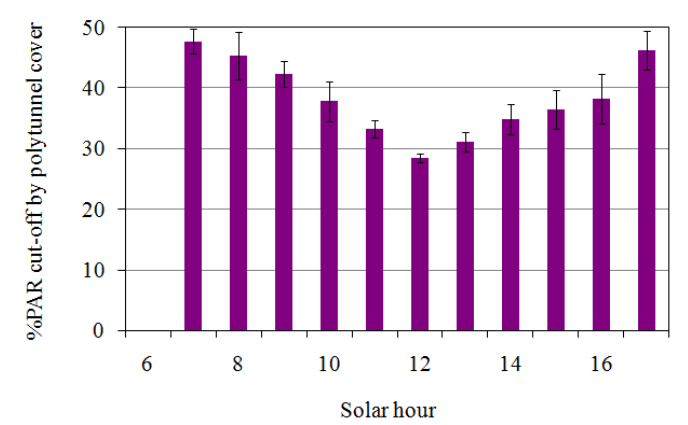

e

Fig. 3. Percentage of cut-off photosynthetically active radiation (PAR) by low-tech cover at various dates of measurements. Vertical bar represents the standard deviation $( \pm)$ of mean $(n=3)$. Solar hour refers the Bangladesh Standard Time = Greenwich Mean Time $($ GMT $)+6$ Hours. Overcast sky after 10th hour: (a) 4 November 2016; Fine sky throughout day: (b) 19 November 2016; (c) 20 November 2015; (d) 5 December 2017 ; (e) 10 December 2016. The dates are arranged as per sequence of the number of Day of Year (DOY).

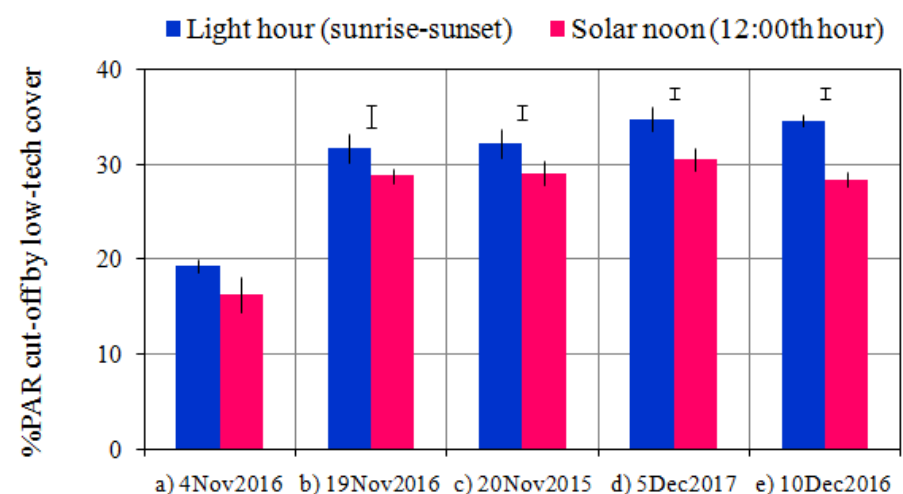

Fig. 4. Percentage of photosynthetically active radiation (PAR) cut-off by low-tech cover during solar noon time and throughout the day from sunrise to sunset (total light hours). Attached vertical bars (without cap) represent the standard deviation $( \pm)$ of mean $(n=3)$ and detached vertical bars (capped) represent the Least Significant Difference (LSD) at $1 \%$ level (except $\left.{ }^{*} P<0.05\right)$ of probability. NS $=$ Not significant. The dates are arranged as per sequence of the number of Day of Year (DOY). The sky remained overcast after $10^{\text {th }}$ hour on 4-Nov-2016 while the other dates remained fine throughout the day. 


\section{B. Diurnal Time-course of Air Temperature}

Air temperature remains low during night hours. From the time of sunset, it gradually decreases over the nighttime and get lowest value just prior to sunrise (Fig. 5). Air temperature has a direct relation with solar radiation and is sensitive to even small fluctuation of sunlight. Thus, soon after sunrise, air temperature rapidly increases with the advancement of the day and gets to a peak around 13:00 hour while solar radiation gets peak around 12:00 hour. That is, the daytime pattern of air temperature follows the pattern of solar radiation with about one hour time lag to get its peak. Diurnal pattern shows that low-tech retains higher air temperature than that found outside of the low-tech structure (Fig. 5). However, the variation of air temperature between inside and outside of low-tech was gradually increased after sunrise and maximum variation was recorded following the solar noon (Fig. 6).

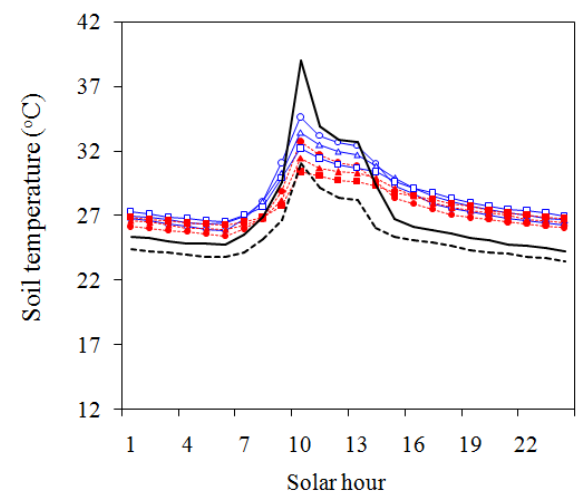

a

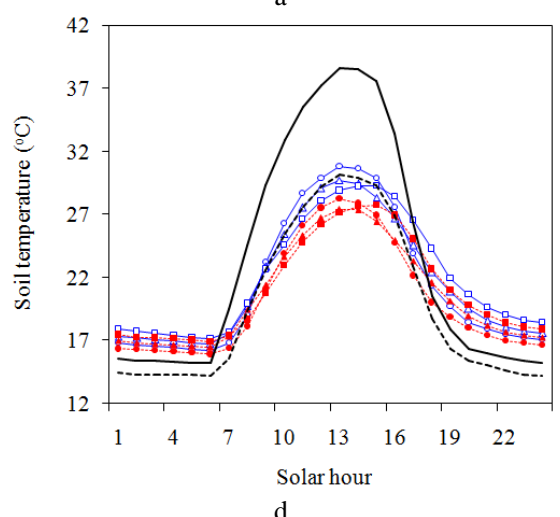

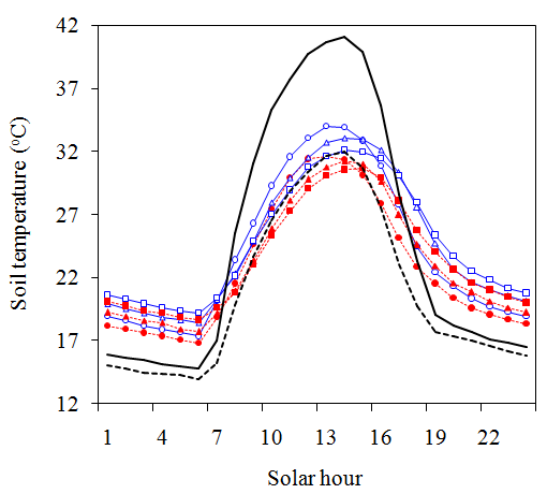

b

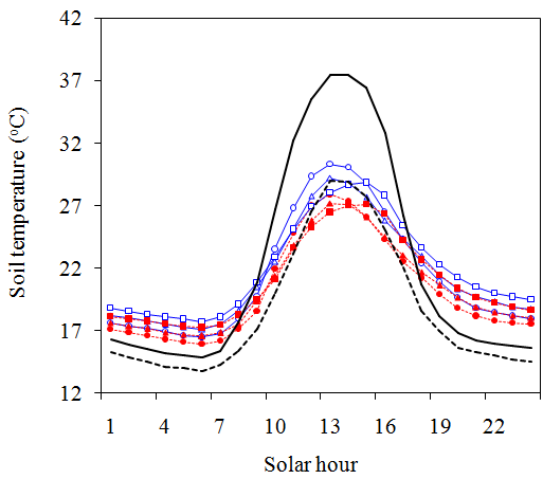

e

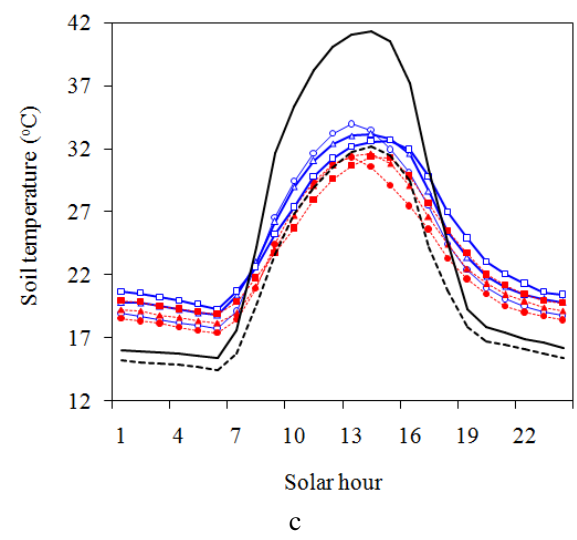

$\multimap$ Low-tech inside soil, $1 \mathrm{~cm}$

-... Outside soil, $1 \mathrm{~cm}$

$\triangle$ Low-tech inside soil, $5 \mathrm{~cm}$

-... Outside soil, $5 \mathrm{~cm}$

$\rightarrow-$ Low-tech inside soil, $10 \mathrm{~cm}$

-.--Outside soil, $10 \mathrm{~cm}$

- Low-tech inside air

---.. Outside air

Fig. 5. Diurnal cycle of air temperature and soil temperature at 1, 5 and $10 \mathrm{~cm}$ depths between inside and outside of low-tech greenhouse on different days. Each point represents the mean of 3 replications while standard deviation $( \pm)$ of mean is not shown for the sake of clarity. Solar hour refers the Bangladesh Standard Time $=$ Greenwich Mean Time $($ GMT $)+6$ Hours. The sky remained overcast after $10^{\text {th }}$ hour on 4-Nov-2016 while the other dates remained fine throughout the day. (a) 4 November 2016; (b) 19 November 2016; (c) 20 November 2015; (d) 5 December 2017; (e) 10 December 2016. The dates are arranged as per sequence of the number of Day of Year (DOY).

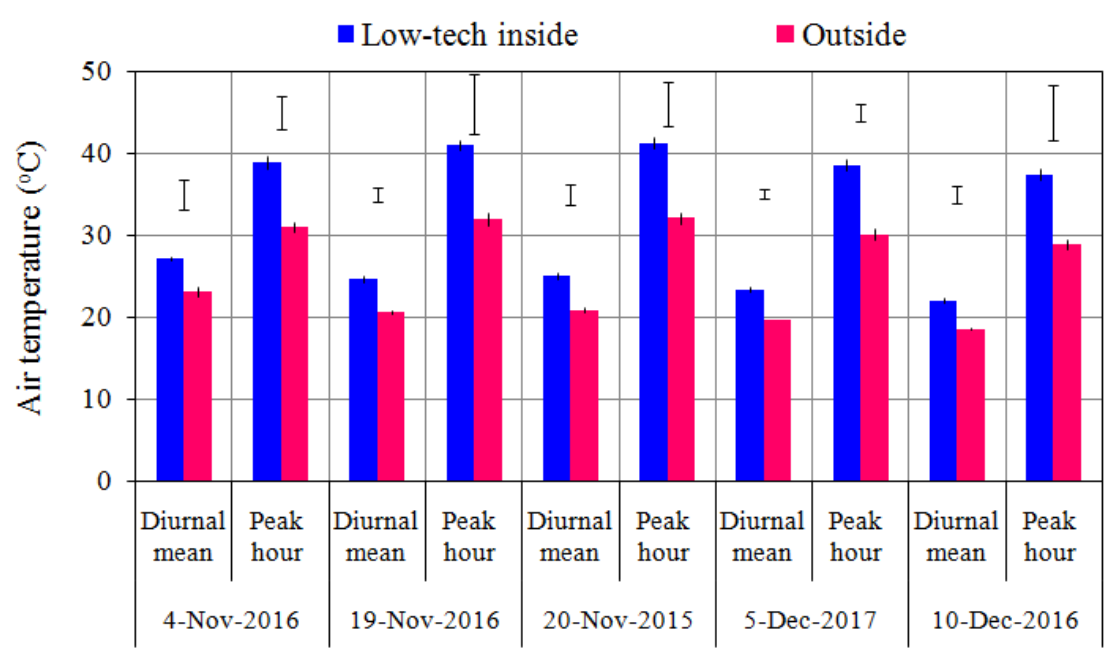

Fig. 6. Air temperature measured at inside and outside of the low-tech. Diurnal mean indicates the average value found from 24 hours of a day while peak hour indicates the value found when air temperature was highest. Attached vertical bar (without cap) represents the standard deviation $( \pm)$ of mean $(n=3)$ while detached vertical bar (capped) represents the Least Significant Difference (LSD) at $1 \%$ level $(P<0.01)$ of probability. The dates are arranged as per sequence of the number of Day of Year (DOY). The sky remained overcast after $10^{\text {th }}$ hour on 4-Nov-2016 while the other dates remained fine throughout the day. 
The daytime and nighttime temperatures were separately analyzed and found that the variation in air temperature between inside and outside of the low-techs was highly significant $P<0.01$ during daytime while during nighttime such variation was little but significant with $P<0.05$ (Table II).

\section{Diurnal Time-course of Soil Temperature and Movement of Heat in Soil}

Soil temperature exhibited as a function of air temperature but with a few hour time-lags to attain its peak value. Soil temperature at $1 \mathrm{~cm}, 5 \mathrm{~cm}$ and $10 \mathrm{~cm}$ depths got peak in 13:00, 14:00 and 15:00 hours (Fig. 5), respectively, while air temperature got peak in 13:00 hour. After reaching the peak, soil temperature rapidly decreased till sunset followed by steadily and slowly declined till just before the sunrise when soil temperature got minimum value in diurnal cycle. Variation in soil temperature between inside and outside of low-tech was minimum during nighttime and maximum during daytime.

Diurnal variation in heat movement was gradually minimized with increasing the depth of soil. In day time, surface (top) soil got warmer than sub-surface (deep) soil both in inside and outside of low-tech but soil at $10 \mathrm{~cm}$ depth retained high temperature during nighttime compared to that at $1 \mathrm{~cm}$ depth. The soil temperature inversion was occurred during 10:00 AM when heat (as reflected by the value of temperature) in $1 \mathrm{~cm}$ depth superseded the heat that retained at $10 \mathrm{~cm}$ depth. An opposite inversion of heat was occurred at 16:00 hour (4:00 PM) when soil heat in $1 \mathrm{~cm}$ depth rapidly looses than the heat at $10 \mathrm{~cm}$ depth of soil. Soil temperature at $5 \mathrm{~cm}$ depth showed the intermediate value that found in $1 \mathrm{~cm}$ and $10 \mathrm{~cm}$ depths of soil. Temperature of soil outside the low-tech showed rapid or quick oscillation than the temperature of soil inside the lowtech. Irrespective of the depths, soil under low-tech cover showed higher temperature as compared to that recorded in nearby soil outside the low-tech. Such variation in soil temperature was found lower during night hours but higher during the day hours. The aforesaid variation in soil temperature was found insignificant when the sky remained overcast (Fig. 5a) as compared to that at sunny days (Fig. 5b-e).

\section{Diurnal Time-course of Relative Humidity}

Relative humidity $(\mathrm{RH})$ represents the ratio of amount of water vapor actually present in air to maximum amount of water vapor held by air at same temperature. That is, it is the ratio of the partial pressure of water vapor to the equilibrium vapor. A higher percentage of RH means that the air-water mixture is more humid. During night especially from 19:00 (7:00 PM) to 6:00 hours (during morning), the RH was 100 percent i.e., air was fully saturated with water vapour and is at its dew point (Fig. 7). Results reveal that the differences in RH between inside and outside of the low-tech was very little or insignificant during nighttime. With progressing of daytime, the RH gradually reduced to get an off-peak (lowest RH) hour after solar noon. In an overcast and windy day (5.38 kmph as observed in 4 November 2016) (Table I), no distinct diurnal pattern of $\mathrm{RH}$ and its variation was observed between inside and outside of low-tech (Fig. 7a). However in any sunny day, the variation of RH between inside and outside of low-tech during daytime hours was lowest (Fig. 7b-e). The relative humidity from diurnal mean and that observed in off-peak hour was also not varied between the inside and outside of low-tech (Fig. 8).

\section{DISCUSSION}

Sunlight, the electromagnetic radiation acts as a unique source of energy or heat for earth-environment system. The sunlight consists of short-wave radiation $(0.3-3.0 \mu \mathrm{m})$ that can easily penetrate and pass through the polyethylene film used in roof and wall of the low-tech greenhouse. At the same time, poly-film also resists photosynthetically active radiation (PAR) $(0.4-0.7 \mu \mathrm{m})$ as much as 30 to 40 percent to transmit it into the low-tech tunnel [12]. This result corresponds to our findings. This declined in light intensity as much as 30 to 50 percent inside the low-tech greenhouse compared to that at the nearby open field was also reported by many researchers [5],[15-17]. Moreover during winter time, when the low-tech technology is being used or to be used, naturally it receives low light intensity due to short day length and sun low in the sky. Therefore, in winter overall reduction in PAR inside the low-tech may be a barrier for optimum growth and development of crops especially C4 species. Nevertheless, the C3 species that covered about $85 \%$ crop plants support photosynthesis with a lower light intensity [18]. It is possible to provide supplemental light but research-based recommendations specifically for cost-effective lighting for winter crop production in low-tech are scanty [19]. Extra light can also be supplied by installing solar panel systems with compromising some initial investment. New researchers could investigate this matter.

TABLE II: NIGHT- AND DAYTIME AIR TEMPERATURE UNDER INSIDE LOW-TECH AND THAT AT OUTSIDE IN DIFFERENT DATES OF MEASUREMENT

\begin{tabular}{|c|c|c|c|c|c|c|c|c|c|c|}
\hline \multirow{3}{*}{ Treatments } & \multicolumn{10}{|c|}{ Measurement date (DOY) $)^{\mathrm{a}}$} \\
\hline & \multicolumn{2}{|c|}{4 Nov 2016 (309) } & \multicolumn{2}{|c|}{19 Nov $2016(324)$} & \multicolumn{2}{|c|}{20 Nov 2015 (324) } & \multicolumn{2}{|c|}{5 Dec 2017 (339) } & \multicolumn{2}{|c|}{10 Dec $2016(345)$} \\
\hline & Night time & Day time & $\begin{array}{l}\text { Night } \\
\text { time }\end{array}$ & Day time & $\begin{array}{l}\text { Night } \\
\text { time }\end{array}$ & $\begin{array}{l}\text { Day } \\
\text { time }\end{array}$ & $\begin{array}{l}\text { Night } \\
\text { time }\end{array}$ & Day time & Night time & Day time \\
\hline Outside & $24.0 \pm 0.1$ & $26.7 \pm 0.2$ & $15.9 \pm 0.3$ & $26.3 \pm 0.3$ & $15.6 \pm 0.3$ & $26.3 \pm 0.5$ & $15.0 \pm 0.2$ & $25.4 \pm 0.2$ & $15.1 \pm 0.3$ & $22.6 \pm 0.5$ \\
\hline $\mathrm{LSD}_{0.01}$ & $0.46^{*}$ & 1.59 & $0.44^{*}$ & 2.78 & $0.84^{*}$ & 2.83 & $0.59^{*}$ & 1.05 & $0.51^{*}$ & 5.38 \\
\hline
\end{tabular}

${ }^{\mathrm{a}}$ Arranged as per sequence of the number of Day of Year (DOY) as shown in parenthesis.

Figure following the \pm sign represent the standard deviation (SD) of mean $(n=3)$.

$\mathrm{LSD}_{0.01}$ indicates the Least Significant Difference between the values found from inside and outside of the low-tech at $1 \%$ level (except $\left.{ }^{*} P<0.05\right)$ of probability. 


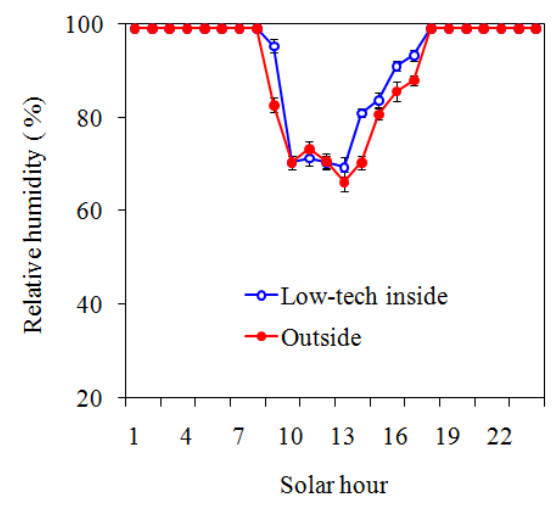

a

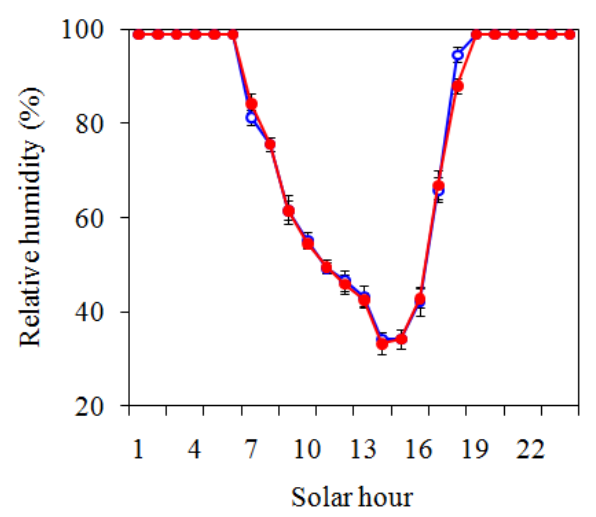

d
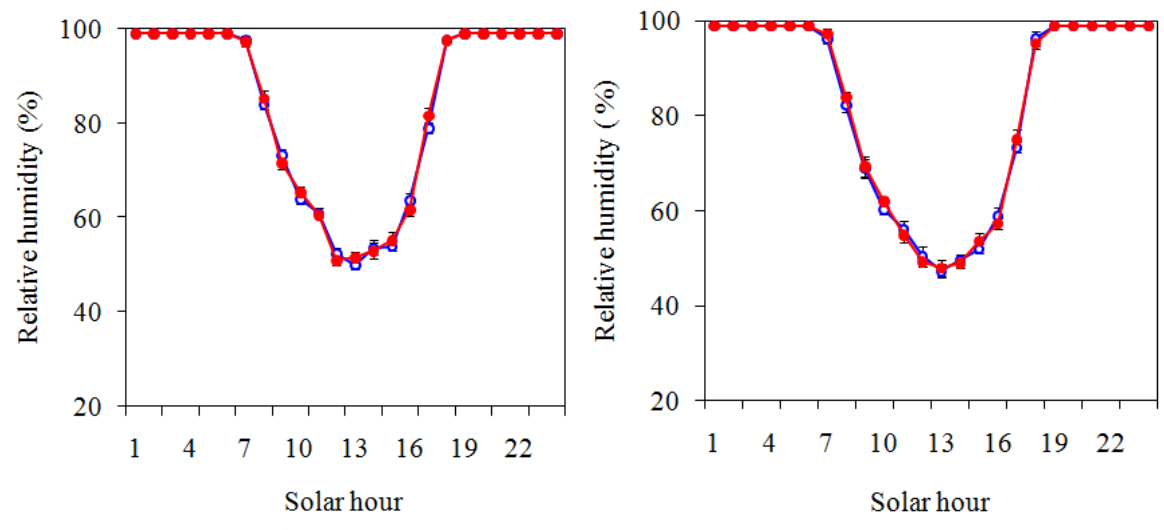

b

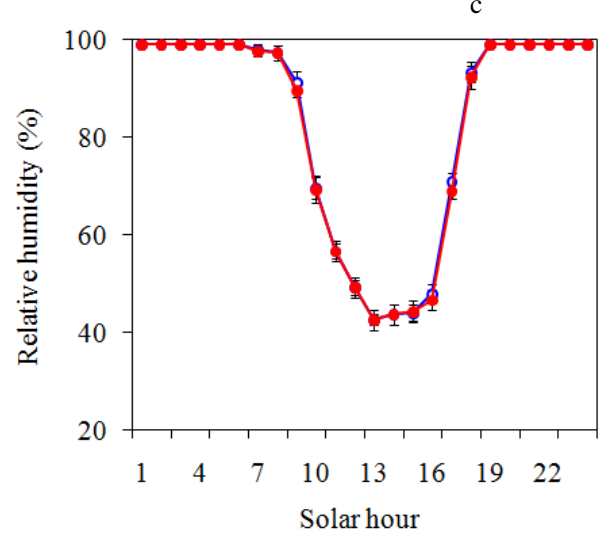

e

Fig. 7. Diurnal time course of relative humidity under low-tech and that found in outside at various dates of measurements. Vertical bar represents the standard deviation $( \pm)$ of mean $(n=3)$. Solar hour refers the Bangladesh Standard Time $=$ Greenwich Mean Time $($ GMT $)+6$ Hours. Overcast sky after $10^{\text {th }}$ hour: (a) 4 November 2016; Fine sky throughout day: (b) 19 November 2016; (c) 20 November 2015; (d) 5 December 2017 ; (e) 10 December 2016. The dates are arranged as per sequence of the number of Day of Year (DOY).

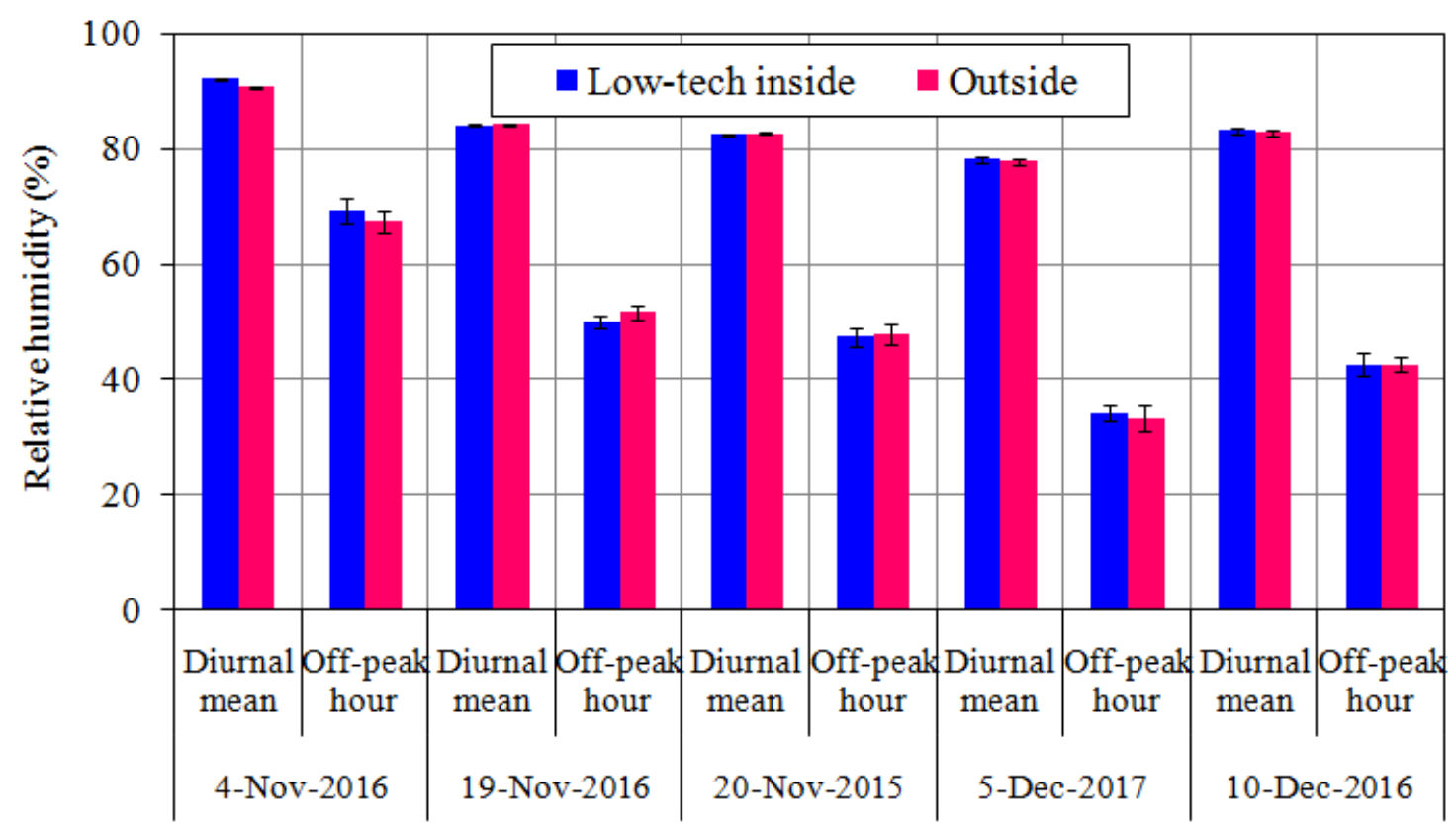

Fig. 8. Relative humidity (RH) measured at inside and outside of the low-tech. Diurnal mean indicates the average value found from 24 hours of a day while off-peak hour indicates the value found when RH was lowest. Vertical bar represents the standard deviation $( \pm)$ of mean $(n=3)$. The dates are arranged as per sequence of the number of Day of Year (DOY). The sky remained overcast after $10^{\text {th }}$ hour on 4-Nov-2016 while the other dates remained fine throughout the day.

Soon after the sunlight gets into the low-tech to strike soil or crop plants therein, the energy from short-wave solar radiation converts into heat energy to release as long wave or thermal radiation which cannot gets out of the polyethylene film for their poor penetration power and thus, the thermal radiation is trapped inside the low-tech [18]. As a result temperature inside the low-tech is increased and the process is called the greenhouse effect [20]. Therefore, daytime air temperature inside the low-tech goes far above as much as 3 to $20^{\circ} \mathrm{C}$ than that found outside of the low-tech [3], [13],[15], [16], [21], [22]. During the nighttime as the source of sunlight is disappeared and concomitant diffusion 
of previously trapped heat inside the low-tech is occurred that led to create little or no variation in air temperature than that at outside. The minimum influence of low-tech cover on modifying the relative humidity is attributed due to the non air-tight conditions of tunnel structure and the finding is corroborated with the results reported by [3] and [17]. However, the relative humidity was found higher in a controlled hi-tech greenhouse [1] with an average 4.7 percent maximum and 10.6 percent minimum values [23].

Elevated air temperature under low-tech had induced increment in soil temperature. Simply, soil temperature is directly related to air temperature. Studies have shown that soil temperature inside the plastic low tunnel is $2-5^{\circ} \mathrm{C}$ higher than temperature recorded in open field soil [13], [21]. The result is also supported by [3]. Virtually, root or rhizosphere temperature is assumed to be the same as the soil temperature that has significant influence on crop growth and productivity [24]-[26]. Thus, soil temperature should be taken into account for producing crops inside the low-tech.

Solar energy is the sole agent to create variation in heat and temperature of an object and thus air temperature is directly changed with intensity of solar radiation. So, daytime course of air temperature follows the distribution pattern of solar radiation with about one to two hours time lags in a diurnal cycle [27]. Heat in air influences soil to change its temperature and thus air temperature remains higher than soil temperature during the day hours. During night, air temperature quickly drops due to the absence of sun but soil loses heat slowly. Thus soil temperature at night hours remains higher than air temperature because the rate of heat dissipation by the sub-layer soils is slower than that from surface (ground) soil or atmosphere [18]. That's why soil temperature in night hours had a little change with soil depth. Thus, deeper the soil, greater the stability against the soil temperature change. Therefore, diurnal change of soil temperature is gradually leveled-off with depth.

Low-techs are mainly used in temperate regions alike to greenhouses and cloches (row covers). But in summer, temperatures under low-tech may be too high for some crops. Thus, effective ventilation system should be created during sitting the low-tech structure to dissipate heat load and vapour. Greenhouse fitted with fan and pad system can bring down the temperature by $10-12{ }^{\circ} \mathrm{C}$ [28]. Top ridge and side ventilation also gives good fresh air exchange and lowers the temperature [23]. Thus a low-tech not only increases the temperature but the system could also reduce the temperature inside it. The reduced temperature could bring suitable environment during summer season for growing many crops those need lower temperature than the ambient one. Thus the low-tech greenhouse can be used to extend the growing season whatever the crops need to elevate or to reduce the temperature. Such type of protected cultivation using low-tech structure creates a favourable environment to obtain a yield that is as close to maximum as possible [10].

Off-season cultivation has gained popularity among the vegetable growers of the world [9]. Low-tech is a cheap and better way for off-season production technology and can be utilized for year round (i.e., season extended) vegetable cultivation of high value crops such as parthenocarpic cucumber, muskmelon, capsicum, virus free high quality seedlings, quality hybrid seed etc. The technology has attracted considerable research interest as it can improve fruit precocity due to forcing on earlier flowering and fruiting [22], [29]. So, low-tech greenhouse caters to season extended and off-season production of vegetables and farmers can get fetch or premium price of their products.

Low-tech greenhouse has spread in recent years because it protects crops from the damage due to bright sunlight, intense heat, strong winds, hailstones, cold waves and frost etc. [15], [30] and even it can kill the unwanted fungi, viruses, bacteria etc. to sterilize soil by generating immense heat within it. It can also be used as a tool for disease resistance breeding programmes [31], [32].

\section{CONCLUSION}

Low-cost or low-tech greenhouse can remarkably modify the microclimate inside it. It creates warmer environment required for growing high value horticultural crops like cucumber, tomato, strawberry, watermelon, okra etc. during winter (off season) in Bangladesh when ambient temperature often falls below the cardinal limits of those crops. Thus this simple technology can effectively be used for season extension and/or off-season production of high value crops to make them available with premium price round the year in Bangladesh.

\section{ACKNOWLEDGEMENT}

This work was partially financed by the Bangladesh Agricultural University Research System (BAURES), BAU, Mymensingh 2202.

\section{COMPETING INTERESTS}

Authors have declared that no competing interests exist.

\section{REFERENCES}

[1] S. Singh, D. R. Singh, A. Velmurugan, I. Jaisankar, T. P. Swarnam Coping with climatic uncertainties through improved production technologies in tropical island conditions. In: Biodiversity and Climate Change Adaptation in Tropical Islands. C. Sivaperuman, A Velmurugan, A. K. Singh, I. Jaisankar (Eds.). Elsevier Inc., pp. 623 666,2018

[2] T. Blomgren, T. Frisch. High tunnels: using low-cost technology to increase yields, improve quality and extend the season. SARE (Sustainable Agriculture Research and Education), 2007. Retrieved on 20 July 2020.

[3] A. Singh, A. Syndor, B. C. Deka, R. K. Singh, R. K. Patel. The effect of microclimate inside low tunnels on off season production of strawberry (Frageria $\times$ Anamosa Duch.). Scientia Horticulturae, 2012;144: 36-41.

[4] W. J. Lamont Jr. Overview of the use of high tunnels worldwide. HortTechnology, 2009;19(1):25-29. https://doi.org/10.21273/HORTSCI.19.1.25.

[5] G. Rogers. An investigation of low-cost protective cropping VG13075. Horticulture Innovation Australia - Final Report. Applied Horticultural Research, 2018.

[6] M. L. Engel, P. C. F. Junior, A. C. Ikeda, G. B. de Alcantara, A. R. Higa. Use of mini polytunnels for the maintenance of a clone garden of Acacia mearnsii De Wildeman in different seasons of the year. Revista FLORESTA, 2018;48(4):601-608. https://doi.org/10.5380/rf.v48i4.57602.

[7] [7]S. A. Adams, K. A. Todd, "High tunnel design, site development, and construction", The Board of Regents of the University of 
Nebraska on behalf of the University of Nebraska-Lincoln Extension, 2015.

[8] L. Sagar. Exotic and uncommon vegetable production in poly tunnels. In: Protected Cultivation and Smart Agriculture. S. Maitra, D.J. Gaikwad, T. Shankar (Eds.). New Delhi Publishers, New Delhi: 2020, pp. 146-160. https://doi.org/10.30954/NDP-PCSA.2020.15.

[9] V. S. Negi, R. K. Maikhuri, L. S. Rawat, D. Parshwan. Protected cultivation as an option of livelihood in mountain region of central Himalaya, India. The International Journal of Sustainable Development and World Ecology, 2013;20(5):416-425. https://doi.org/10.1080/13504509.2013.799103.

[10] P. Dahiya, K. Singh. Polyhouse Farming: A New Concept of Agriculture. Bhartiya Krishi Anusandhan Patrika, 2018;33:109-112. https://arccjournals.com/journal/bhartiya-krishi-anusandhanpatrika/BKAP971; 2018. accessed on 15 September 2021.

[11] H. C. Wien. Microenvironmental variations within the high tunnel. Horticultural Science, 2009; 44: 235-238.

[12] J. S. Cowan, C. A. Miles, P. K. Andrews, D. A. Inglis. Biodegradable mulch performed comparably to polyethylene in high tunnel tomato (Solanum lycopersicum L) production. Journal of the Science of Food and Agriculture, 2014;94:1854-1864. https://doi.org/10.1002/jsfa.6504.

[13] Y. Zhao, M. Gu, G. B. Evans, R. Harkess. Planting date effect on yield of tomato, eggplant, pepper, zinnia, and snapdragon in high tunnel in Mississippi. Journal of Crop Improvement, 2014;28: 27-37. https://doi.org/10.1080/15427528.2013.858283.

[14] D. F. Russel, "MSTAT-C Package Programme. Crop and Soil Science Department, Michigan State University, USA. 1986.

[15] G. P. Mishra, N. Singh, H. Kumar, S. B. Singh. Protected cultivation for food and nutritional security at Ladakh. Defence Science Journal, 2010;60 (2):219-225.

[16] M. Job. Study on changes in microclimatic parameters under polyhouse with different color plastic mulching during tomato cultivation Journal of Pharmacognosy and Phytochemistry, SP1: 689-694, 2018.

[17] H. C. Anderson, M. A. Rogers, E. E. Hoover. Low tunnel covering and microclimate, fruit yield, and quality in an organic strawberry production system. HortTechnology, 2019;29(5):590-598. https://doi.org/10.21273/HORTTECH04319-19.

[18] N. J. Rosenberg, B. L. Blad, S. B. Verma. Microclimate: The Biological Environment. Second Edition, John Wiley \& Sons Inc., 1983.

[19] E. Maynard, M. O'Donnell. Managing the environment in high tunnels for cool season vegetable production. Horticulture \& Landscape Architecture, High Tunnel Series, HO-297-W. Purdue University Extension. 2019. https://www.extension.purdue.edu/extmedia/HO/HO-297-W.pdf; accessed on 17 September 2021.

[20] A. Ollila. The Greenhouse Effect Definition. Physical Science International Journal, 2019;23(2):1-5. https://doi.org/10.9734/PSIJ/2019/v23i230149.

[21] A. B. Ogden, M. W. Van Iersel. Southern highbush blueberry production in high tunnels: temperatures, development, yield, and fruit quality during the establishment years. Horticultural Science, 2009;44:1850-1856.

[22] A. Jinu, V. M. Abdul Hakkim. Performance of a low cost automation system for greenhouse cooling. International Journal of Current Research, 2018;10(08):72158-72163.

[23] K. C. Priya, Er. I. Bhagat, N. Kumar. Influence of climatic parameters on performance of carnation (Dianthus caryophyllus L.) under protected cultivation. International Journal of Chemical Studies, 2018;6(3):1599-1602.

[24] M. A. Awal, M. A. H. Khan. Alteration of soil temperature and moisture through mulching on the morpho-physiological differentiation in maize. Pakistan Journal of Biological Sciences, 1999;2(4):1164-1167. https://doi.org/10.3923/pjbs.1999.1164.1167.

[25] M. A. Awal, M. A. H. Khan. Mulch induced eco-physiologica growth and yield of maize. Pakistan Journal of Biological Sciences, 2000;2(4):61-64. https://doi.org/10.3923/pjbs.2000.61.64

[26] M. A. Awal, T. Ikeda. Controlling canopy formation, flowering, and yield in field-grown stands of peanut (Arachis hypogaea L.) with ambient and regulated soil temperature. Field Crops Research, 2003;81(2-3). https://doi.org/10.1016/S0378-4290(02)00216-2.

[27] O. O. Soneye, M. A. Ayoola, I. A. Ajao, O. O. Jegede. Diurnal and seasonal variations of the incoming solar radiation flux at a tropical station, Ile-Ife, Nigeria. Heliyon, 2019;5(5):e01673. https://doi.org/10.1016/j.heliyon.2019.e01673.

[28] H. Oz, A. Atilgan, B. Buyuktas, T. Alagoz. The efficiency of fan-pad cooling system in greenhouse and building up of internal greenhouse temperature map. African Journal of Biotechnology, 2009;8(20): 5436-5444.
[29] K. Demchak. Small fruit production in high tunnels. HortTechnology, 2009;19(1):44-49.

[30] S. Singh, A. K. Saxena. Protected cultivation of summer squash in mid-hills of Uttarakhand. Journal of Horticultural Science and Research, 2020;3(1):82-85.

[31] B. Singh, M. Kumar, N. P. S. Sirohi. Protected cultivation of cucurbits under low-cost protected structure: a sustainable technology for peri-urban areas of northern India. Acta Horticulturae, 2007;31 267-272.

[32] N. Kumar, G. Singh. Protected cultivation of parthenocarpic brinjal (Solanum melongena L.). International Journal of Agriculture Innovations and Research, 2015;4(1):105-106.

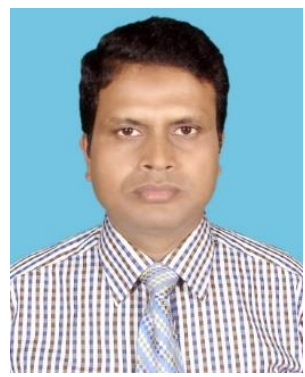

M. A. Awal was born in Tangail district of Bangladesh on January 1, 1971. He grew up with spending his childhood in his own village, Baimail of Mirzapur sub-district where he completed the primary level education in 1980. Subsequently he completed his secondary education from Mirzapur S.K High School in 1986 and higher secondary education from Mirzapur College in 1988 with securing first division in each examination. Thereafter he admitted to Bangladesh Agricultural University, Mymensingh and passed the Bachelor of Science in Agriculture degree in 1992 with first class $4^{\text {th }}$ place in order of merit out of 448 students. He continued at the same University, where, later, in 1997, he took his Masters of Science degree with first class with distinction $(\mathrm{A}+)$ in Crop Botany.

Years later, Awal awarded the competitive 'Jin-nai International Student Scholarship Program' for conducting doctoral study in Niigata University, Japan where he worked on how soil temperature affects the pheno-phase development, source-sink relationship, radiation-use efficiency and yield of peanut crop in cool temperate climate. He successfully earned the Doctor of Philosophy (Ph.D.) degree in 2003 on Environmental Management Science with publishing six interesting scientific articles in some world famous journals like Journal of Agronomy and Crop Science, Environmental and Experimental Botany, Field Crops Research, and Agricultural and Forest Meteorology. Due to the glorious achievements from his Ph.D. research, Dr. Awal soon awarded the most competitive JSPS Postdoctoral Fellowship in Nagoya University of Japan from 2004 to 2006 for conducting the joint research on how urbanization affects the carbon dioxide flux and carbon sequestration between the forest ecosystem and atmosphere and the research output is published in great journals like Urban Forestry \& Urban Greening, and Science Postprint. Till now he supervised about 30 postgraduate students and wrote sixty scientific articles which are published in different national and international journals. Due to the outstanding contribution in science Awal's Bibliography is published in the Silver Anniversary of Who'sWho in the World on 2008: a Who'sWho in America Publication, Marquis Who's Who LLC, $25^{\text {th }}$ Edition, page 117.

Awal's career as a teacher started in 1997, when he was recruited as a Lecturer in the Department of Crop Botany under the Faculty of Agriculture of Bangladesh Agricultural University (BAU). Serving in same department he was appointed as an Assistant Professor in 2000, Associate Professor in 2004 and Professor in 2009, and finally Selection Grade Professor in 2020. He additionally served as a Curator of the Botanical Garden of BAU from 2012 to 2014 where a vast spectrum of plant diversity including endangered and threatened species is reared. Prof. Awal also completed the tenure of Headship \& Chairman, Board of Studies from 2014 to 2016 in the Department of Crop Botany, BAU.

Professor Awal is engaged to various professional societies like Japan Crop Science Society (2001-2002), Japanese Forestry Society (2005-2006), the Society of Agricultural Meteorology of Japan (2005-2006), and American Meteorological Society (2005-2008) as member. Currently he is a member of AsiaFLUXnet (http://www.asiaflux.net), Japan from 2005 to date. Dr. Awal is a life member of Bangladesh JSPS Alumni Association (BJSPSAA) and Japanese Universities Alumni Association in Bangladesh (JUAAB). He attended to many national and international seminars, symposia, workshops, training courses etc. Prof. Awal is working as Editorial Board Member of some scientific journals and he often reviews the articles of journals from home and abroad. He is devoted to conduct research on climate change and environment and food security issues and recently he is engaged to various project works on underlying discipline. His main hobby is gardening. 